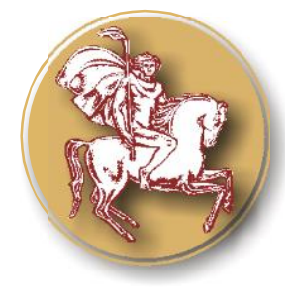

Trakia Journal of Sciences, No 4, pp 294-301, 2021

Copyright (C) 2021 Trakia University

Available online at:

http://www.uni-sz.bg

ISSN 1313-3551 (online)

doi:10.15547/tjs.2021.04.002

\title{
STUDY ON THE LEVEL OF DISASTER PREPAREDNESS AMONG VETERINARY PRACTITIONERS
}

\author{
G. Balieva ${ }^{1 *}$, V. Ivanov ${ }^{2}$ \\ ${ }^{1}$ Department of Hygiene, Technology and Control of Food Products of Animal Origin, Veterinary \\ Legislation and Management, Faculty of Veterinary Medicine, Trakia University, Stara Zagora, Bulgaria \\ ${ }^{2}$ Department of Chemistry and Biochemistry and Section of Medicine of the Disaster Situation, Faculty of \\ Medicine, Trakia University, Stara Zagora, Bulgaria
}

\begin{abstract}
PURPOSE: This study was focused on veterinary practitioners in Bulgaria with the aim to investigate and present their level of preparedness for disaster response and continuance of professional activities after disaster events. METHODS: A sociological survey through a questionnaire with open and closed questions was sent to veterinarians throughout the country personally or via e-mail. RESULTS: Veterinary practitioners in Bulgaria are not legally engaged in disaster prevention, excluding the prevention of contagious animal diseases. At the same, time veterinarians could assist the population not only in case of biological contamination but also in any crisis situation caused by natural, technical, and human factors. The study showed that one-third $(34.38 \%, \mathrm{n}=11)$ of the respondents had supplied their practices with emergency equipment, while $75 \%(n=24)$ of them had secured the continuity of communications. Another $21.88 \%(n=7)$ of respondents had arranged in advance a meeting place for staff after evacuation to meet and plan the reorganization of their activities. Only $3.13 \%(n=1)$ of the respondents had conducted simulated evacuations in arranged training. CONCLUSIONS: The findings could be used for drafting guidelines and teaching materials for professional training, enhancing the veterinary practitioners to perform more effectively in emergencies and thus raise the disaster resilience of the community as a whole.
\end{abstract}

Key words: disaster resilience; disaster risk reduction; veterinary practices; resources; labour standards.

\section{INTRODUCTION}

Disaster resilience is characterized by the ability of the population to predict, to cope with, and to recover from disastrous events. The biggest challenge in such cases appeared to be the protection of life, property and vital infrastructure. Common in all disaster situations were issues related to the functioning of an early warning system; food and water provisions; health and decontamination; collection and proper disposal of waste; ensuring

*Correspondence to: Gergana Nikolova Balieva, Department of Hygiene, Technology and Control of Food Products of Animal Origin, Veterinary Legislation and Management, Faculty of Veterinary Medicine, Trakia University, Stara Zagora 6000, Bulgaria; email: gnikolova.vet@gmail.com sustainable shelters; power supply; information, communication and transport infrastructure.

Considering the residents of a particular village as an integral part of the overall system for disaster preparedness, Taha et al. (1) investigated the awareness and the role of the population in managing disasters and crises at a local level. The authors` survey found relatively good but still insufficient level of awareness and understanding of the concepts of civil protection and crisis management among the respondents concerning indicators such as evacuation, hygiene, communication.

The necessity of building awareness of disaster protection among the society in Bulgaria through training, experience, research and innovations 
was discussed by Slavova et al. (2) in their survey on public awareness as an element of the general mechanism for disaster risk reduction.

Given that the effects of natural and technical disasters could affect every professional group in society to a certain extent, different authors measured the knowledge, attitude and practices available for disaster management among representatives from the healthcare sector. Similar studies were conducted among dental practitioners and academics (3), nurses (4), pharmacists (5), employees in emergency health centres (6), and in public health system structures (7).

\section{PURPOSE OF THE STUDY}

The multifunctional dimensions of veterinary medicine and its important role for the whole process of disaster management, made it reasonable to examine the available resources of the private veterinary sector in Bulgaria, necessary for ensuring the safety of staff and practice and the preparedness to maintain business continuity in case of disaster situation. The study aimed also to investigate the level of awareness of veterinary practitioners on disaster preparedness activities within their practices.

\section{MATERIALS AND METHODS}

For the purpose of the study a questionnaire with open and closed questions was prepared, using the methodology of the empiric sociological
BALIEVA G., et al. survey (8). The questionnaire was distributed from July to December 2018 to 134 veterinarians throughout the country personally or via e-mail. The completed and returned questionnaires were 32 in total (response rate $-23.89 \%$ ). All data received were processed with IBM SPSS Statistics (SPSS-Inc., 2019, SPSS Reference Guide 26 SPSS, Chicago, USA), using descriptive statistics (frequency distribution tables), correlation analysis (Pearson correlation coefficient) and Student's t-test (t-test for independent samples). The results from the analysis (at $\mathrm{p}<0.05$ ) were used to formulate conclusions relevant for the veterinary practitioners in the country.

\section{RESULTS}

In order to establish the level of commitment to and the interest of veterinary practitioners in the activities for disaster preparedness, the respondents were distributed by a sphere of professional activity and by their status as employees or business owners. The largest share of respondents, $58.33 \%(\mathrm{n}=19)$, worked with companion animals (mainly representatives from big and medium-sized cities in the country, some of them - administrative centres), followed by mixed type of practice $-33.33 \%(n=10)$, while practitioners working with production animals were $8.33 \%(n=3)$ (located mainly in the small towns and rural areas). (Figure 1)

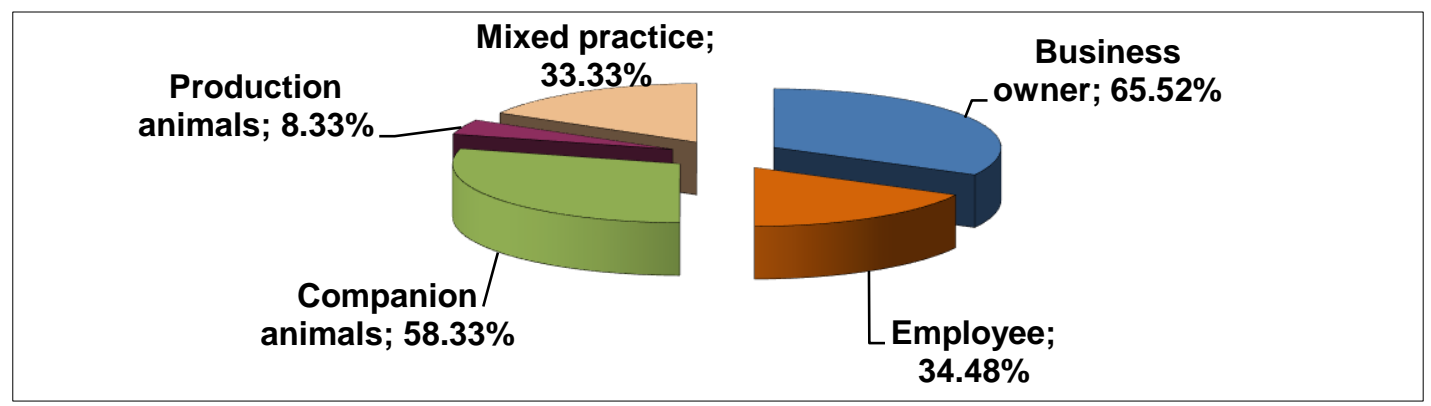

Figure 1. Respondents` distribution by sphere of professional activity and employment status

Data from the study showed that $65.52 \%(\mathrm{n}=21)$ of the respondents appeared to be owners or partners in the veterinary practice where they worked at. They were in fact decision-makers and managed all activities carried out in their practice, including planning, preparation, response during a disaster and recovery after that. Student`s t-test found significant difference in favour of veterinary practitioners - business owners and the group of respondents who declared to be able to maintain continuance in communication during and after disaster outbreak $(\mathrm{t}[29]=-3.43$; $\mathrm{p}<0.05)$. The remaining share of $34.48 \%(\mathrm{n}=11)$ were employees, veterinarians who were part of 
the practice staff and participants in the implementation of the plan for disaster preparedness and response.

The analysis of the information from the questionnaire showed that within $62.50 \%(n=20)$ of the veterinary practices there had been developed comprehensive action plans for disasters and emergencies. On the contrary, over half of the respondents - $53.13 \%(n=17)$ -
BALIEVA G., et al. declared lack of necessity to get prepared to respond to emergency situations. Data also showed that there was a significant positive correlation between the share of the veterinarians who had developed action plan and the share of those who had arranged relocation of their business within an alternative practice $(r=0.57$ at $\mathrm{p}<0.05$ ), and had stored personal medications for 3-5 days for the veterinarians and the other staff at the clinic ( $\mathrm{r}=0.57$ at $\mathrm{p}<0.05)$. (Figure 2)

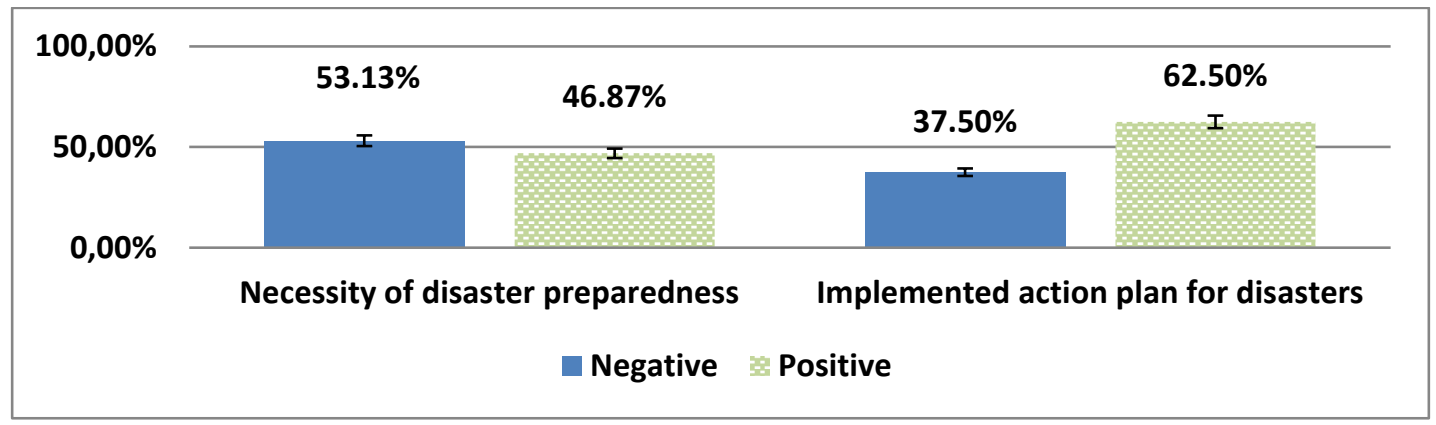

Figure 2. Respondents` distribution by indicators ,implemented action plan for disasters“and „,necessity of disaster preparedness“"

Given the obligatory requirements for operation and exploitation of an enterprise, necessary for registration of a veterinary practice $(9), 71.88 \%$ $(n=23)$ of respondents stated they were familiar with the specific requirements for safety, more than half of them $-53.13 \%(n=17)$ - had drawn plan of the floor with marked fire-extinguishers, hazardous areas and evacuation routes on it, and the same proportion of respondents $53.13 \%$ $(n=17)$ had secured exits for evacuation in case of emergency. In fact, a significant difference was found in favour of veterinary practitioners business owners and the group of respondents who declared their awareness of the specific safety rules at the work place $(\mathrm{t}[29]=-3.10$; $\mathrm{p}<0.05$ ). (Figure 3)

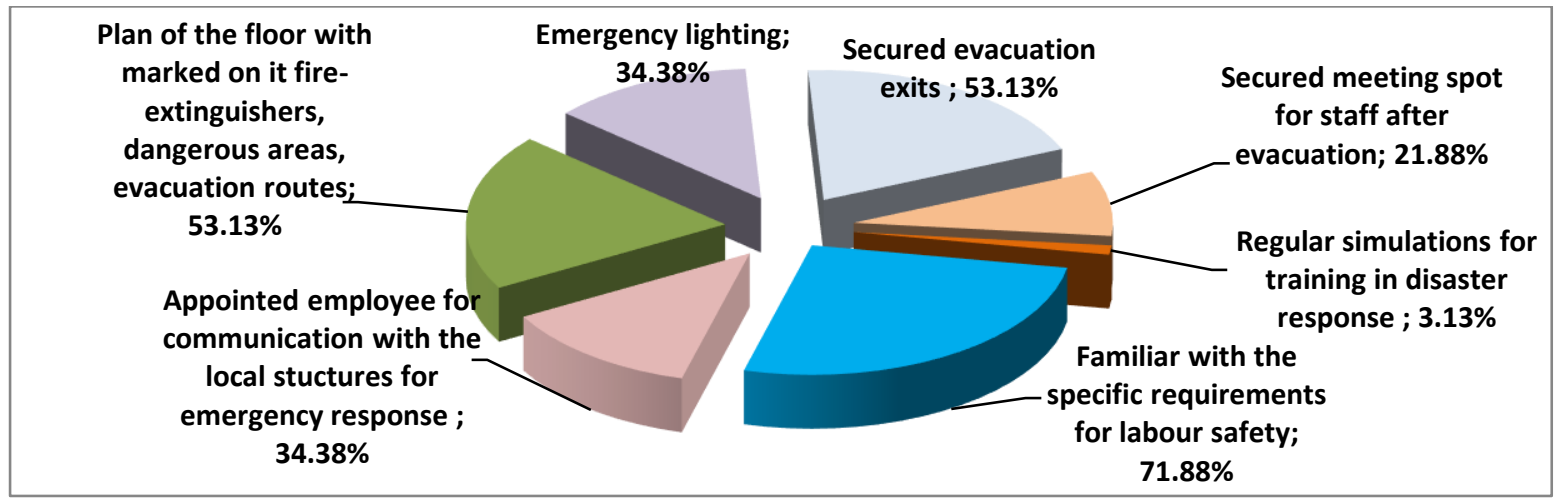

Figure 3. Aspects for ensuring safety of staff within the veterinary practices during disasters

Only one-third of respondents had secured their practices with emergency lighting (34.38\%, $\mathrm{n}=11$ ) and had appointed an employee to communicate with the local structures for emergency response and civil protection (again $34.38 \%$ of respondents, $n=11$ ).
Significantly smaller share get the veterinarians who had arranged and secured in advance a meeting place for staff after evacuation $-21.88 \%$ $(n=7)$ of respondents. Such a place could be any location inside or outside the disaster area where employees would be able to gather, assess the situation, discuss the damages, allocate the 
available resources and plan the reorganization of their activities.

Whether the respondents were really prepared for disaster situations could be determined after the analysis of the available resources for maintenance continuity of their professional activities. The results showed that the highest
BALIEVA G., et al. share of $75 \% \quad(n=24)$ get the veterinary practitioners who had secured the continuity of communications in any crisis situation. However, it appeared that they were less likely to prepare in advance a distant meeting place for the employees after evacuation - there was a negative correlation $-r=-0.46(p<0.05)$. (Figure 4)

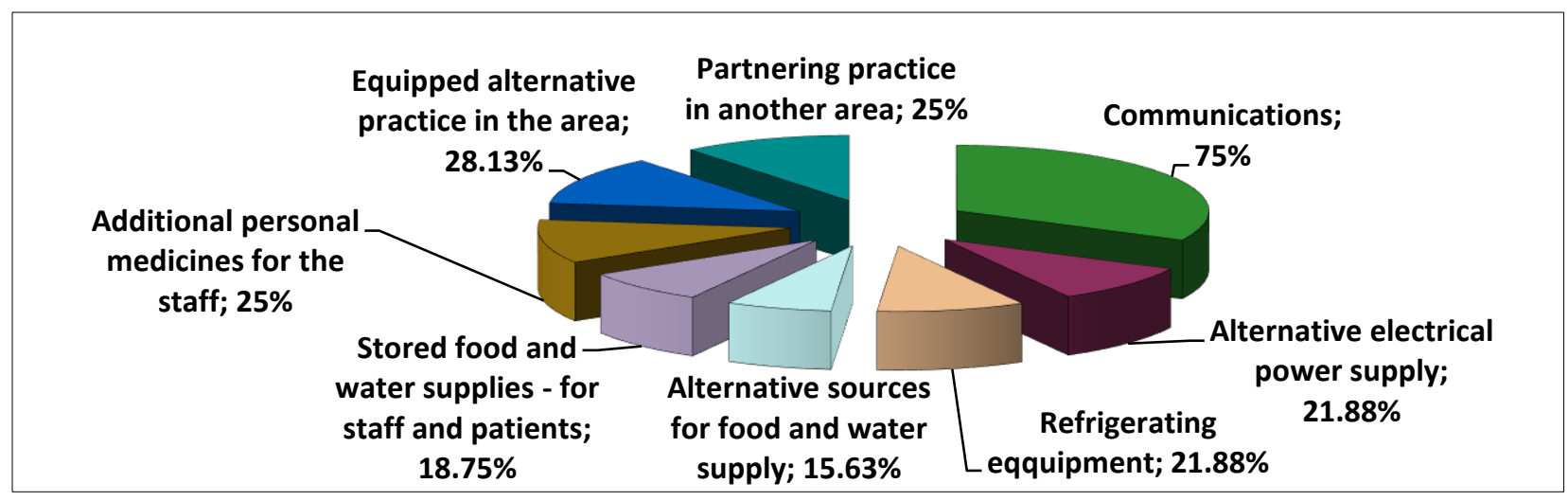

Figure 4. Ability to maintain business continuity of the veterinary practices during disaster

In case of severe events when the practices would have to be closed $28.13 \% \quad(n=9)$ of the veterinarians shared they had provided reorganization and relocation of their business through the equipment of an alternative site within the same residence. An additional option to this relocation appeared to be the signing of a contract with a partnering veterinary practice situated in another village - preferred by $25 \%$ $(n=8)$ of the respondents. The decision for equipment of an alternative practice was statistically dependent on the ownership of the practice, as there was a positive correlation $r=0.46(p<0.05)$, between this indicator and the position of the respondents as business owners.

The survey showed that ensuring the continuity of all manipulations and operations within the clinic during a disaster was dependent on the availability of certain facilities and supplies. In regard to this, veterinary practices should have the following equipment:

- Alternative electric power supply within the practice and the staff should be familiar with the terms of its exploitation and maintenance. Veterinarians who had equipped their practices with a generator were $21.88 \% \quad(n=7)$ of the respondents;
- Reserve refrigerating equipment at the clinic (for bioproducts, etc.) - available at $21.88 \%$ $(n=7)$ of the practices;

- Stored personal medications for 3-5 days for the veterinarians and the other staff at the clinic, regarding their personal health status $-25 \%(n=8)$ of respondents;

- Stored food and water supplies for staff and patients for 3-5 days - provided by $18.75 \%(n=6)$ of the respondents;

- Alternative sources of food and water for the staff and the patients in case of contamination of the existing ones - provided by $15.63 \%(n=5)$ of the respondents.

\section{DISCUSSION}

In Bulgaria, under the current legal framework for disaster risk reduction (10) had been developed and implemented a National Strategy for reducing the risk of disasters 2018-2030 (11), which had to identify strategic priorities for action and to support the implementation of measures for their execution at national, regional, municipal and establishment level. The cited documents set out general parameters for operation within which professional competencies of veterinarians were of significance in case of a risk of biological contamination, for assessment of safety of livestock production in order to be used for food 
and feed, for ensuring the supply of foodstuffs for shelters in disaster areas, in all activities for prevention of contamination of the environment. In fact,the veterinarians from the private sector were not legally engaged in the prevention and management of disasters. This statement found indirect confirmation by the Law on Disaster Protection, that regulated the structure of the established and operating in the country Integrated Rescue System (12).

The absence of legal texts that clearly determined the regular participation of veterinary practitioners in the disaster risk reduction activities, did not allow the society to effectively benefit from their professional skills to increase the sustainability of the entire community. Similarly, Wittnich \& Belanger (13) pointed out the lack of adequate procedures in the Canadian Federal Emergency Response Plan for the evacuation of animals together with their owners, thus addressing the formation of the Canadian Veterinary Reserve for response to disasters of all types. Leyland et al. (14) also identified gaps in policy and strategy on the role of public and private veterinary sectors. On the other hand, a wide range of examples on the vital role of the veterinary practices were presented in studies on evacuation activities among the population from disaster areas, who while saving their own lives sought opportunities for evacuation and care for their pets, incl. horses (15-17).

In order to provide professional support to the community and at the same time to protect their lives, property and business, veterinarians had to be prepared to act effectively during crisis situations. Such preparedness in advance declared $62.50 \%$ of our respondents, who had developed a comprehensive action plan for disasters and emergencies, but, on the other hand, more than half of them $-53.13 \%$ claimed they did not need to be prepared for emergencies. This "contradiction" might find its explanation in the fact that the development of an evacuation plan was a prerequisite for operation, legally regulated by the Law on Health and Safety at Work (18) and valid for all professional spheres of activity in the public and private sectors. A similar study on the level of consistency between the regulatory requirements for disaster preparedness and their actual application had made Dunnick et al. (6), who focused on medical health centres in the
BALIEVA G., et al. United States. Their results showed that $27 \%$ of these centres had implemented a plan for disaster management which also included other communities in the residence.

The level of disaster preparedness of veterinary practitioners in Bulgaria regarding safety at the workplace, could be described as relatively good as $71.88 \%$ of the respondents were familiar with the legal requirements for work safety, and $53.13 \%$ of them had an evacuation plan of the practice with secured evacuation routes and exits in case of emergency. The importance of staff well-being was addressed also in the study of Whitman et al. (19) as one of the major concerns for organisations recovering after an earthquake. Regarding the business continuity in the private veterinary sector, $75 \%$ of our respondents stated they had secured the continuity of communications in any crisis situation. In this case, communication flowed between the employees of the practice, between the staff and the clients/animal owners, as well as communication with local structures for emergency response and other stakeholders participating in the disaster management chain. However, the declared communication continuity had not been tested in a real crisis situation, thus could not be accepted as an absolute statement. Sood et al. (20) had made similar conclusions based on a study of 46 health care centres before and after Hurricane Sandy in 2014. The authors reported that less than a quarter of the respondents had developed a plan for business continuity before the hurricane, while during the disaster all respondents had registered electrical power problems causing a disruption in land communications, fax and Internet.

Analysing the preparedness of veterinary clinics and dispensaries for work during a disaster, it became clear by our survey that only $28.13 \%$ of the colleagues had provided reorganization and relocation of their business through the equipment of an alternative site within the same area. This initiative logically could be completed by large reputable veterinary practices with established permanent client flow from big cities or regional administrative centres, practices that have financial resources for equipment of another branch of the clinic. The owners of such veterinary clinics had an additional professional interest in such an initiative, as in terms of 
disaster they could take patients and clients of other practices which had to close. Subsequently, it could be expected from some of the assisted clients to become their regular customers, and prefer the services of the clinic as more reliable than the rest in the city.

An alternative to the launch of a second enterprise was the signing of a contract with a partnering veterinary practice located in another residence, preferred by $25 \%$ of our respondents. Such a choice was an indicator of smart strategic planning and management of the practice as: it did not lead to additional financial expenses for the clinic / dispensary; it gave an opportunity in future, in circumstances of loyal partnership, the business to be expanded through opening a branch or affiliate company in another town; the partnering practice was located in another area, which was supposed to be unaffected by the disaster and would be in operation to provide adequate and effective veterinary services. For comparison, Sood et al. (20) argued that in 2014 during the Hurricane Sandy $95 \%$ of the surveyed health care centres in the area had to suspend or relocate their activities.

Our opinion was consistent with that of Whitman et al. (19) who found that after an earthquake for the affected organizations the most helpful factors in mitigating the disastrous effects appeared to be their relationship with staff members, the design and type of buildings, and critical service continuity or swift reinstatement of services.

The indicator that appeared to be of a great significance for the preparedness of veterinary practices for disaster response was the regular training conducted in simulated crisis situations independently or jointly with other structures. A similar example of a project developed for joint cooperation for disaster risk reduction gave Sim et al. (21) who analyzed the implementation of a first aid training programme of health and social workers, including 22 local professional and business organizations. Although only $3.13 \%$ of the respondents in our survey had conducted simulated evacuations in an arranged training situation, this segment of veterinarians seemed to be most prepared for managing and recovery of business activities after the event. In support to our opinion appeared to be the study of Lai et al.
BALIEVA G., et al. (22) who analysed the level of knowledge of 39 residents before and after a simulated crisis situation. The authors stated that crisis management competences of the participants had improved after the simulation. Arguments towards raising knowledge and skills in civil protection and first aid in emergency situations were given also by Slavova (23) who recommended specialized training and simulation exercises in various hazards affecting significant sites from the public infrastructure.

\section{CONCLUSION}

The study of the private veterinary sector showed that veterinarians as a part of the civil population in a disaster situation should first of all take care for the safety of their own lives, staff and property, which reaction is largely influenced by their level of awareness, preparedness for evacuation and communication capabilities. On the other hand, as health professionals veterinary practitioners appeared to be an important link in the chain for providing resources to the community in order to overcome and recover from the disastrous event, giving assistance in evacuation and rescue works, providing healthcare and advice to animal owners.

Regarding the implemented and functioning legislative regulations for disaster management, and the analyzed state of preparedness for disaster response of the veterinary practitioners in Bulgaria, it could logically be assumed that professional veterinary competences might successfully be implemented as components of the Unified rescue system for disaster prevention, management and recovery from disastrous events. This would help the whole community to raise its sustainability to crisis situations by utilizing its own resources optimally, as veterinary practices appeared to be part of these material and non-material resources. For this purpose, the role of the veterinarians for disaster risk reduction should be legally determined and regulated. On this basis various information and teaching materials could be prepared for professional training, enhancing the veterinary practitioners to perform more effectively in emergencies.

\section{ACKNOWLEDGMENTS}

The authors would like to thank all veterinary practitioners throughout the country who 
voluntarily participated in the study and filled in the questionnaire. This research was a part of the University Scientific Project 07/2016 funded by the Ministry of Education and Science.

\section{REFERENCES}

1. Taha, V. A., Tej J., Sirkova M., Živčák P. Crisis awareness of the municipal district residents: Implication for crisis management at the local government level. Quality Innovation Prosperity Vol. 18 (Iss. 2):pp. 114, 2014.

2. Slavova V., Dimitrova D., Ivanov V., Parashkevova B., Vasileva A., Platikanova M. State policy for training the population for protective actions during disastrous situations, International research journal, №4 (46), pp.. 122-124, 2016.

3. Pandita, V., Basavaraj P., Singla A., Gupta R., Kaur R., Vashishtha V., Prasad M., Kumar J. K. Recasting Disaster Recovery Strategy at Dental Workplace in Combating Crisis - A Questionnaire Study. Journal of Clinical and Diagnostic Research;10(4):ZC39-44, 2016.

4. Veenema, T., Griffin A., Gable A., Larson E. Nurses as Leaders in Disaster Preparedness and Response-A Call to Action. J Nurs Scholarsh;48(2):187-200, 2016.

5. Ford, H., Dallas C. E., Harris C. A. Examining Roles Pharmacists Assume in Disasters: A Content Analytic Approach. Disaster Medicine and Public Health Preparedness, 7(6):1-10, 2013.

6. Dunnick, J., Olympia R. P., Wilkinson R., Brady J. Low Compliance of Urgent Care Centers in the United States With Recommendations for Office-Based Disaster Preparedness. Pediatric Emergency Care 32(5):298-302, 2016.

7. Kohn, S., Semon N., Hedlin H., Barnett D. J. Public health-specific personal disaster preparedness training: An academic-practice collaboration. Journal of Emergency Management 12(1):55-73, 2014.

8. Orloev, N. Research methodology. Rousse: Centre for higher education training and management (Bg). 2002.

9. Anonymous, Ministry of Labour and Social Policy, Ministry of Health (MLSP, MH). Directive № 7 of 23.09.1999 on the minimal requirements for health and safety conditions at workplaces and the use of working
BALIEVA G., et al. equipment. Off. Gazette 88/8.10.1999, amend. Off. Gaz. 95/29.11.2016. (Bg). 1999.

10.Anonymous, United Nations Office for Disaster Risk Reduction (UNISDR). Sendai Framework for Disaster Risk Reduction 2015 - 2030. Available at: http://www.unisdr.org/files/43291_sendaifra meworkfordrren.pdf (Accessed 12 January 2019). 2016.

11.Anonymous, Council of Ministers (CM). National Strategy on disaster risk reduction 2018 - 2030. Available at: http://strategy.bg/FileHandler.ashx?fileId=17 617 (Accessed 6 February 2019) (Bg). 2018.

12. Anonymous, National Assembly (NA). Law on disaster protection. Off. Gaz. 102/19.12.2006, amend. Off. Gaz. 81/14.10.2016. (Bg). 2006.

13.Wittnich, C., Belanger, M. How Is Animal Welfare Addressed in Canada's Emergency Response Plans? Journal of Applied Animal Welfare Science 11(2):125-32, 2008.

14.Leyland, T., Lotira, R., Abebe, D., Bekele, G., Catley, A. Community-based Animal Health Workers in the Horn of Africa: An Evaluaton for the US Office for Foreign Disaster Assistance. Feinstein International Center, Tufts University Africa Regional Office, Addis Ababa and Vetwork UK, Great Holland. 2014.

15.Case, H. Animals in Emergency Management: Veterinary Medical Triage and Treatment. Prehospital and Disaster Medicine, 26 (S1): S90-S90, 2011.

16. Mcclure, D. E., Kerr J. Evolution of Pet Owner Disaster Preparedness - California Wildfires from 2003 to 2009. Prehospital and Disaster Medicine, Volume 26 Issue S1: 147, 2011.

17.Hesterberg, U., Huertas G., Appleby M. C. (2012). Perceptions of pet owners in urban Latin America on protection of their animals during disasters. Disaster Prevention and Management, 21(1):37-50, 2012.

18. Anonymous, National Assembly (NA). Law on healthy and safety labour conditions. Off. Gaz.124/23.12.1997, amend. Off. Gaz.79/13.10.2015. (Bg). 1997.

19. Whitman, Z., Stevenson, J., Kachali, H., Seville, E., Vargo, J., Wilson, T. Organisational resilience following the 
Darfield earthquake of 2010. Disasters 38(1):148-77, 2014.

20.Sood, R. K., Bocour A., Kumar S., Shah T. B. Impact on Primary Care Access Post-Disaster: A Case Study From the Rockaway Peninsula. Disaster Medicine and Public Health Preparedness -1:1-4, 2016.

21.Sim, T., Liu Y., Li S. (2016). Working together: Developing disaster risk reduction first aid training in a post-earthquake Chinese context. Journal of Social Work, 17 (4): 491497, 2016.
BALIEVA G., et al.

22.Lai, A., Haligua Al., Bould M. D., Everett T., Gale M., Pigford A. A., Boet S. Learning Crisis Resource Management: Practicing versus an Observational Role in Simulation Training - A Randomized Controlled Trial. Anaesthesia, Critical Care \& Pain Medicine; 35(4):275-81, 2016.

23. Slavova, V. Readiness of the population for protection and first medical aid during disaster situation in the region of Stara Zagora. Dissertation, p. 62. Trakia University - Stara Zagora, Bulgaria, 2016. 